University of Wollongong

Research Online

Australian Institute for Innovative Materials -

Papers

Australian Institute for Innovative Materials

2003

Improving the mechanical properties of single-walled carbon nanotube sheets by intercalation of polymeric adhesives

Jonathan N. Coleman

Trinity College Dublin

Werner J. Blau

Trinity College Dublin

Alan B. Dalton

University of Texas at Dallas

Edgar Munoz

University of Texas at Dallas

Steve Collins

University of Texas at Dallas

See next page for additional authors

Follow this and additional works at: https://ro.uow.edu.au/aiimpapers

Part of the Engineering Commons, and the Physical Sciences and Mathematics Commons

Research Online is the open access institutional repository for the University of Wollongong. For further information contact the UOW Library: research-pubs@uow.edu.au 


\title{
Improving the mechanical properties of single-walled carbon nanotube sheets by intercalation of polymeric adhesives
}

\author{
Abstract \\ Organic polymers, such as poly(vinyl alcohol), poly(vinyl pyrrolidone), and poly(styrene), were intercalated \\ into single-walled carbon nanotube sheets by soaking the sheets in polymer solutions. Even for short \\ soak times, significant polymer intercalation into existing free volume was observed. Tensile tests on \\ intercalated sheets showed that the Young's modulus, strength, and toughness increased by factors of 3 , \\ 9 , and 28 , respectively, indicating that the intercalated polymer enhances load transmission between \\ nanotubes.

\section{Keywords} \\ intercalation, sheets, nanotube, carbon, walled, mechanical, improving, properties, single, adhesives, \\ polymeric \\ Disciplines \\ Engineering | Physical Sciences and Mathematics

\section{Publication Details} \\ Coleman, J. N., Blau, W. J., Dalton, A. B., Munoz, E., Collins, S., Kim, B. G., Razal, J., Selvidge, M., Vieiro, G. \& \\ Baughman, R. H. (2003). Improving the mechanical properties of single-walled carbon nanotube sheets by \\ intercalation of polymeric adhesives. Applied Physics Letters, 82 (11), 1682-1684.
}

\section{Authors}

Jonathan N. Coleman, Werner J. Blau, Alan B. Dalton, Edgar Munoz, Steve Collins, Bog G. Kim, Joselito M. Razal, Miles Selvidge, Guillermo Vieiro, and Ray Baughman 


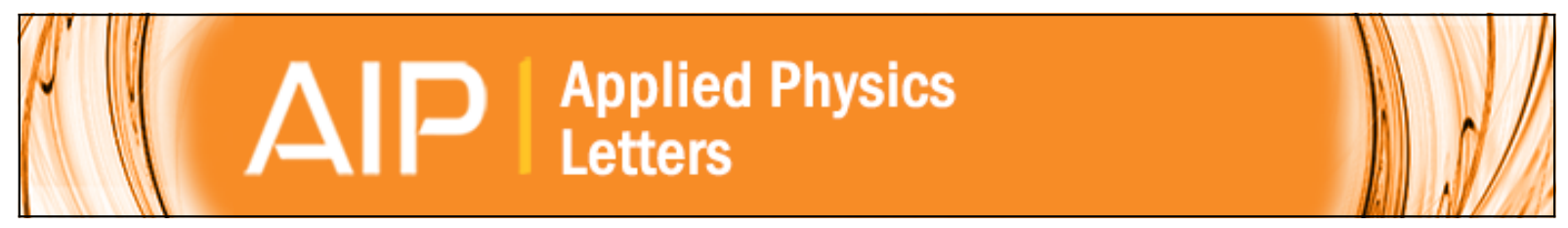

\section{Improving the mechanical properties of single-walled carbon nanotube sheets by intercalation of polymeric adhesives}

Jonathan N. Coleman, Werner J. Blau, Alan B. Dalton, Edgar Muñoz, Steve Collins, Bog G. Kim, Joselito Razal, Miles Selvidge, Guillermo Vieiro, and Ray H. Baughman

Citation: Applied Physics Letters 82, 1682 (2003); doi: 10.1063/1.1559421

View online: http://dx.doi.org/10.1063/1.1559421

View Table of Contents: http://scitation.aip.org/content/aip/journal/apl/82/11?ver=pdfcov

Published by the AIP Publishing

\section{Articles you may be interested in}

Adhesion-driven buckling of single-walled carbon nanotube bundles

J. Appl. Phys. 107, 104305 (2010); 10.1063/1.3374469

Adhesion and reinforcement in carbon nanotube polymer composite

Appl. Phys. Lett. 88, 093108 (2006); 10.1063/1.2181188

Optical properties of intercalated singlewall carbon nanotubes

AIP Conf. Proc. 685, 127 (2003); 10.1063/1.1628001

Electronic structure of intercalated singlewall carbon nanotubes

AIP Conf. Proc. 633, 267 (2002); 10.1063/1.1514120

Improved structure and properties of single-wall carbon nanotube spun fibers

Appl. Phys. Lett. 81, 1210 (2002); 10.1063/1.1497706

\section{A|P| Journal of}

Journal of Applied Physics is pleased to announce André Anders as its new Editor-in-Chief 


\title{
Improving the mechanical properties of single-walled carbon nanotube sheets by intercalation of polymeric adhesives
}

\author{
Jonathan N. Coleman ${ }^{\mathrm{a})}$ and Werner J. Blau \\ Materials Ireland Polymer Research Centre, Department of Physics, Trinity College Dublin, \\ Dublin 2, Ireland
}

Alan B. Dalton, Edgar Muñoz, Steve Collins, Bog G. Kim, Joselito Razal, Miles Selvidge, Guillermo Vieiro, and Ray H. Baughman

UTD NanoTech Institute, The University of Texas at Dallas, P.O. Box 830688, BE 26, Richardson, Texas 75083-0688

(Received 1 November 2002; accepted 17 January 2003)

\begin{abstract}
Organic polymers, such as poly(vinyl alcohol), poly(vinyl pyrrolidone), and poly(styrene), were intercalated into single-walled carbon nanotube sheets by soaking the sheets in polymer solutions. Even for short soak times, significant polymer intercalation into existing free volume was observed. Tensile tests on intercalated sheets showed that the Young's modulus, strength, and toughness increased by factors of 3,9, and 28, respectively, indicating that the intercalated polymer enhances load transmission between nanotubes. (C) 2003 American Institute of Physics.
\end{abstract}

[DOI: $10.1063 / 1.1559421]$

Realization of the applications potential of carbon single-walled nanotubes (SWNT) has been hindered by the many difficulties associated with their processing. Fabricating low-density carbon nanotube powder into functional macroscale structures has been a major challenge. Some progress has been made recently with the fabrication of one-, two-, and three-dimensional bulk nanotube material in the form of fibers, ${ }^{1,2}$ sheets, ${ }^{3}$ and Bucky Pearls ${ }^{\mathrm{TM}}$ pellets produced by Carbon Nanotechnologies Incorporated (CNI). However, while individual SWNTs display impressive Young's moduli and strengths of approximately 640 and 40 $\mathrm{GPa}^{4,5}$ respectively, the mechanical properties of the bulk materials remain disappointing. These low-bulk mechanical properties are in part because the individual SWNT usually forms 10-50-nm-diameter bundles that are only weakly bound by van der Waals interactions at junction points.

Both carbon multiwalled nanotubes (MWNTs) and SWNTs have been used as reinforcing agents in polymer and epoxy composites. ${ }^{6-8}$ Ideally, any load applied to the polymer matrix is transferred to the nanotubes. This load transfer relies on effective interfacial stress transfer at the polymernanotube interface, which tends to be polymer dependent. ${ }^{8}$ This reinforcement technique has met with some success, providing increases in Young's modulus by a factor of 1.8 for $1 \mathrm{wt} \%$ loading of MWNTs in poly(vinyl alcohol) $(\mathrm{PVA})^{8}$ and increases in hardness by a factor of 3.5 for $2 \mathrm{wt} \%$ loading of SWNTs in epoxy. ${ }^{7}$

In this letter, we show that the reverse procedure of polymer intercalation can be used to reinforce bulk nanotube materials. Binding agents such as organic polymers can be intercalated into the porous internal structure of nanotube materials such as SWNT sheets (Buckypaper). This intercalation can be obtained by simply soaking the nanotube sheets in polymer solutions. The resulting polymer-intercalated

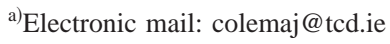

sheets display improvements in Young's modulus and tensile strength by factors of $\sim 3$ and $\sim 9$, respectively.

The nanotube sheets (Buckypaper) used in this work were prepared by filtration of SWNTs dispersed in water and Triton X-100, as previously described. ${ }^{3}$ The SWNTs were made by the HiPco process and supplied by CNI. ${ }^{9}$ This material is known to contain $\sim 20$ wt $\%$ iron $(\sim 2$ vol $\%$ for sheets). The carbon nanotube sheets were annealed under flowing argon at up to $1000{ }^{\circ} \mathrm{C}$ before use, in order to remove residual surfactant, solvents, and contaminants. These sheets were then cut into rectangular strips $(\approx 40 \mu \mathrm{m} \times$ $\approx 2 \mathrm{~mm} \times \approx 2 \mathrm{~cm}$ ) for intercalation with polymer and mechanical testing. Polymer solutions of $5 \mathrm{wt} \%$ PVA in deionized water, 5 wt \% poly(vinyl pyrrolidone) (PVP) in deionized water, and 5 wt \% poly(styrene) (PS) in toluene were prepared by stirring and subsequent sonication. Buckypaper strips were placed in each solution for various times, washed by soaking in deionized water for one hour, and then dried in ambient conditions for $\sim 8$ hours.

Density measurements were made for each sheet using a Perkin Elmer AD6 microbalance for weight measurements, and digital calipers and micrometer for dimensional measurements. Mechanical properties measurements were made using a Perkin Elmer DMA7e. Raman spectroscopy was performed using a JY Horiba HR Labram spectrometer using $632.8 \mathrm{~nm}$ excitation. Both differential scanning calorimetry (DSC) using a Perkin Elmer Diamond DSC (scan rate 10 $\mathrm{K} / \mathrm{min}$ ) and scanning electron microscopy (SEM) with a Leo 1530VP field-emission SEM were carried out on sheets subjected to long soak times. In all cases, thermogravimetric analysis (TGA) was performed using a Perkin Elmer Pyris TGA1 under an oxygen atmosphere (scan rate $20 \mathrm{~K} / \mathrm{min}$ ). The relative contents of iron, SWNTs, and polymer (Table I) were measured for all sheets by determining the residual weight after burning the infiltrated nanotube sheets in a TGA, and from the weight increase resulting from soaking the polymer sheets in the polymer solutions. 
TABLE I. Summary of the data obtained in this study. Column headings are self-explanatory.

\begin{tabular}{lcccc}
\hline \hline $\begin{array}{l}\text { Sample } \\
\text { name }\end{array}$ & $\begin{array}{c}\text { Soak time } \\
{[\text { hours }]}\end{array}$ & $\begin{array}{c}\text { Density } \\
{\left[\mathrm{g} / \mathrm{cm}^{3}\right]}\end{array}$ & $\begin{array}{c}\text { Polymer } \\
\text { weight } \\
{[\%]}\end{array}$ & $\begin{array}{c}\text { Free } \\
\text { volume } \\
{[\%]}\end{array}$ \\
\hline SWNT & $\ldots$ & 0.54 & $\ldots$ & 73 \\
sheet & & & & 68 \\
PVA1 & 2 & 0.62 & 12.8 & 62 \\
PVA2 & 20 & 0.69 & 21.7 & 58 \\
PVA3 & 64 & 0.74 & 26.7 & 71 \\
PVP1 & 2 & 0.56 & 3.6 & 66 \\
PVP2 & 42 & 0.63 & 14.5 & 65 \\
PVP3 & 102 & 0.64 & 16.0 & 69 \\
PS1 & 2 & 0.58 & 6.9 & 58 \\
PS2 & 42 & 0.69 & 22.0 & 66 \\
PS3 & 64 & 0.62 & 12.5 & 6 \\
\hline \hline
\end{tabular}

Shown in Fig. 1 are SEM images of the surface and a cross section for the original sheet and a PS intercalated (42 h) sheet. For the pristine sheet, a porous mat of SWNT ropes is seen on both the surface [Fig. 1(a)] and in the interior (cross-section) [Fig. 1(c)]. For the intercalated sheet, however, it is clear [Fig. 1(b)], that the surface has been coated with polymer, although this coating is relatively thin as pores can still be seen. More importantly, Fig. 1(d) shows that not just the outer region, but the entire internal surface of the nanotube sheet, has been coated with a thin coating of polymer suggesting extensive intercalation.

After soaking and solvent evaporation, the weight and spatial dimensions of each sheet were measured and the density calculated. While the nanotube sheets dimensions do not significantly increase, the density (Table I) increased from
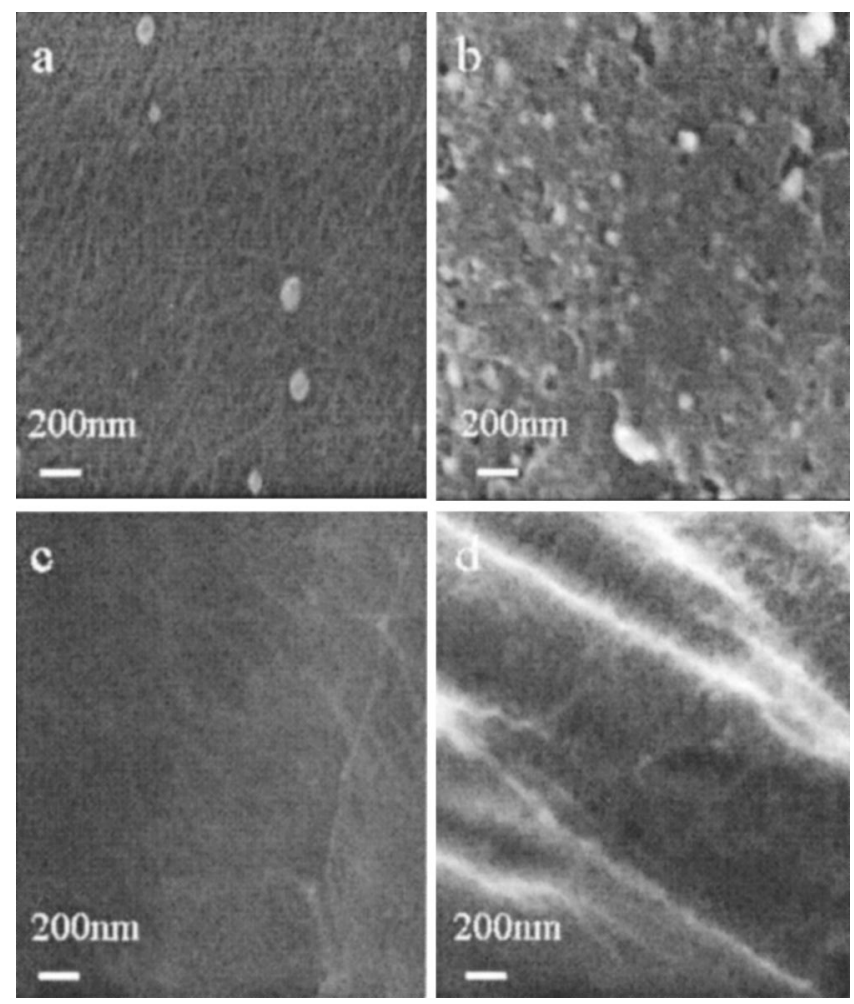

FIG. 1. Scanning electron micrographs of some of the samples used in this study. (a) Surface of pristine nanotube sheet. (b) Surface of PS intercalated (42. h) nanotube sheet (c) Cross section of pristine nanotube sheet. (d) Cross section of PS intercalated nanotube sheet. about $0.54 \mathrm{~g} / \mathrm{cm}^{3}$ for the original annealed sheet to up to 0.74 $\mathrm{g} / \mathrm{cm}^{3}$ (PVA, $64 \mathrm{~h}$ ), indicating intercalation into existing free volume. To investigate this, the percentage free volume (Table I) was calculated for each sheet using the equation

$$
\left(V_{f} / V\right)=I-\rho_{\text {sheet }}\left[\left(p_{\mathrm{NT}} / \rho_{\mathrm{NT}}\right)+\left(p_{\mathrm{P}} / \rho_{\mathrm{p}}\right)+\left(p_{\mathrm{Fe}} / \rho_{\mathrm{Fe}}\right)\right],
$$

where $\rho_{\text {sheet }}$ is the sheet density, $\rho$ is a component density, ${ }^{10}$ $p$ is a component concentration (by mass) and the subscripts NT, P, and Fe refer to SWNT, polymer, and iron components, respectively. The free volume decreased in all cases, from $73 \%$ for the original sheet to $58 \%$ for the PVA $(64 \mathrm{~h})$ sheet, showing that polymer strands tend to intercalate into existing free volume between ropes. However, it is clear that much of the sheet void remains unfilled. Experiments are presently underway to determine the maximum possible level of polymer intercalation.

In order to further study the nature of the intercalation, Raman spectroscopy and DSC (both not shown) were carried out. In the low-frequency region of the Raman spectrum, a number of features associated with the radial breathing modes of the SWNT are observed for all sheets. These features are slightly downshifted by approximately $2 \mathrm{~cm}^{-1}$ for all polymer intercalated sheets compared to the pristine sheets. The small size of the shift suggests the environment of the SWNT has not dramatically changed. However, the presence of a downshift may suggest a weakening of the intertube van der Waals interaction, indicating that polymer chains are beginning to diffuse into the ropes, hence debundling the nanotubes. ${ }^{11}$ The DSC data shows alterations to the melt transition consistent with crystallization of the polymer chains onto the nanotube ropes on intercalation. This is in good agreement with previous studies showing nanotubes acting as nucleation sites for polymer crystal growth. ${ }^{8,12-14}$

Static mechanical properties were measured by DMA for all sheets. Shown in Fig. 2(a) is a typical set of stress-strain curves for the sheets soaked in PVP. In all cases, the Young's modulus $Y$, tensile strength $S$ (stress at break), and toughness $T$ (energy absorbed per unit volume up to break) were calculated from these curves. While the mechanical properties of the pristine sheet were poor $(Y=2.3 \mathrm{GPa}, S=6.29 \mathrm{MPa}$, $\left.T=1.41 \times 10^{4} \mathrm{~J} / \mathrm{m}^{3}\right)$, the properties of the polymer intercalated sheets were significantly increased in all cases. These increases are shown in Figs. 2(b), 2(c), and 2(d) for various loading levels of all polymers. The modulus was virtually polymer independent and increased monotonically with loading level up to $6.9 \mathrm{GPa}$ for the PVA 64-h sample. Similar increases were observed for the strength and toughness with the former increasing by a factor of $\sim 9$ to $57 \mathrm{MPa}$ (PVA 64 h) and the latter increasing by $\sim 30$ to $39 \times 10^{4} \mathrm{~J} / \mathrm{m}^{3}$ (PS 42 h). The strength and toughness data, however displayed a definite trend in relation to the polymer used. In both cases, PS was clearly the best reinforcing agent, followed by PVP, with PVA as a close third. This result is reasonable in terms of the relative hydrophobicities of these polymers. A very hydrophobic polymer like PS is expected to interact more strongly with SWNT than such amphiphilic materials as PVP or PVA, resulting in good stress transfer. Additionally, PVP should interact more readily than the more (locally) polar PVA. 

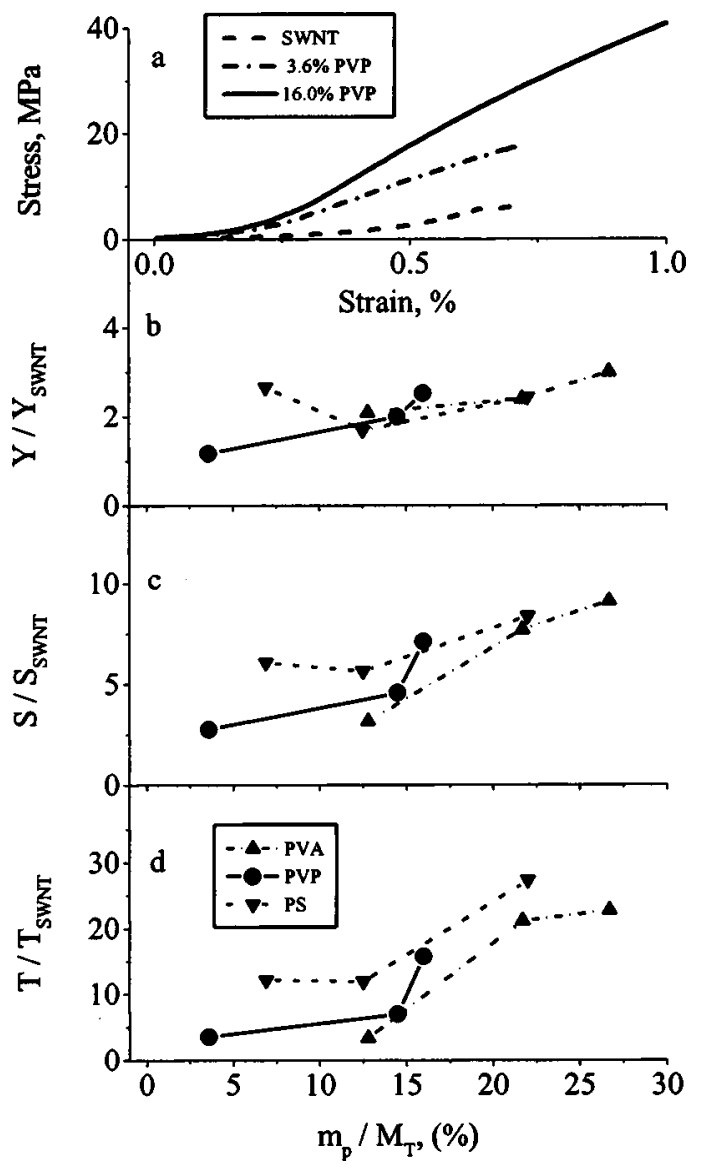

FIG. 2. Summary of the mechanical properties measured in this study. (a) Stress-strain curves for a pristine SWNT sheet and two PVP intercalated sheets, ( 2 h soak, 3.6\% PVP, and 102 h soak, 16.0\% PVP). (b) Normalized Youngs moduli for all the samples measured in this study. (c) Normalized tensile strengths for all the samples measured in this study. Tensile strength is defined as the applied stress at break. (d) Normalized toughness for all the samples measured in this study. Toughness is defined as the energy absorbed by the paper per unit volume up to break. The axis label $m_{\mathrm{p}} / M_{\mathrm{T}}$ is defined as the ratio of polymer content to total sheet mass. The same symbols are used in (b), (c), and (d).

In general, the nature of the reinforcement is thought to be due to the adsorption of polymer strands on the internal surface of the free volume within the sheet. As more polymer intercalates, the thickness of the polymer coating increases. As this proceeds, strands begin to fill the space where adjacent ropes meet. Because the polymer strands tend to crystallize on the nanotube, effective interfacial interaction is expected. ${ }^{8,12-14}$ This results in very high polymer-mediated internanotube stress transfer compared to the polymer-free case, and correspondingly improved macroscopic mechanical properties. As the minimum inter-rope separation is of order $0.34 \mathrm{~nm}$ and the average rope diameter can be approximated as $\sim 35 \mathrm{~nm}$, the amount of polymer needed to begin to reinforce the narrowest inter-rope junctions can be estimated as $\sim 3 \%$. This is compatible with our data, as we see low levels of reinforcement even for the 3.6\% PVP sheet. This shows that mechanical reinforcement in these systems is possible even at very low intercalation levels.
In conclusion, polymer chains can be intercalated into porous nanotube sheets in near equilibrium conditions by soaking in polymer solutions. Significant intercalation has been observed for soak times as short as $2 \mathrm{~h}$. Density and SEM measurements show that the intercalated polymer adsorbs onto the internal surface of existing free volume within the sheets. In all cases, Raman spectroscopy shows that polymer strands have partially diffused between individual nanotubes within the ropes. Overall, intercalation results in the enhancement of inter-rope stress transfer. This strongly modifies the mechanical properties, providing increases in Young's modulus, strength, and toughness by factors of 3, 9, and 28 , respectively.

Partial financial support from Defense Applied Research Projects Agency Grant MDA972-02-C-0005 and the Robert A. Welch Foundation is gratefully acknowledged. Two of the authors (J.N.C. and W.J.B.) would also like to thank the Irish Higher Education Authority, Enterprise Ireland, and the European Union for support.

${ }^{1}$ B. Vigolo, A. Pénicaud, C. Coulon, C. Sauder, R. Pailler, C. Journet, P. Bernier, and P. Poulin, Science 290, 1331 (2000).

${ }^{2}$ A. B. Dalton, S. Collins, E. Muñoz, J. M. Razal, V. H. Ebron, J. P. Ferraris, J. N. Coleman, B. G. Kim, and R. H. Baughman (unpublished).

${ }^{3}$ J. Liu, A. G. Rinzler, H. Dai, J. H. Hafner, R. Kelley Bradley, P. J. Boul, A. Lu, T. Iverson, K. Shelimov, C. B. Huffman, F. Rodriguez-Macias, Y. S. Shon, T. Randall Lee, D. T. Colbert, and R. E. Smalley, Science 280, 1253 (1998)

${ }^{4}$ M.-F. Yu, B. S. Files, S. Arepalli, and R. S. Ruoff, Phys. Rev. Lett. 84, $5552(2000)$

${ }^{5}$ D. A. Walters, L. M. Ericson, M. J. Casavant, J. Liu, D. T. Colbert, K. A. Smith, and R. E. Smalley, Appl. Phys. Lett. 74, 3803 (1999).

${ }^{6}$ D. Qian, E. C. Dickey, R. Andrews, and T. Rantell, Appl. Phys. Lett. 76, 2868 (2000)

${ }^{7}$ M. J. Biercuk, M. C. Llaguno, M. Radosavljevic, J. K. Hyun, and A. T. Johnson, Appl. Phys. Lett. 80, 2767 (2002).

${ }^{8}$ M. Cadek, J. N. Coleman, V. Barron, K. Hedicke, and W. J. Blau, Appl. Phys. Lett. 81, 5123 (2002).

${ }^{9}$ P. Nikolaev, M. J. Bronikowski, R. Kelley Bradley, F. Rohmund, D. T. Colbert, K. A. Smith, and R. E. Smalley, Chem. Phys. Lett. 313, 91 (1999).

${ }^{10}$ The density of SWNT was calculated by considering an $(n, 0)$ SWNT hexagonally close packed in a rope, separated from its neighbors by 0.34 $\mathrm{nm}$. The volume of a unit cell containing $2 n$ atoms was calculated and the resulting density transformed into a function of diameter: $\rho_{\mathrm{SWNT}}$ $=8 \pi D M_{\mathrm{C}} /\left[3 a_{\mathrm{CC}}(D+d)\right]^{2}$, where $D$ is the SWNT diameter, $M_{\mathrm{C}}$ is the mass of a carbon atom, $a_{\mathrm{CC}}$ is the $\mathrm{C}-\mathrm{C}$ bond spacing $(0.142 \mathrm{~nm})$ and $d$ is the van der Waals distance $(0.34 \mathrm{~nm})$. Taking the average Hipco SWNT diameter as $0.8 \mathrm{~nm}$, this gives $\rho_{\mathrm{SWNT}}=1.72 \mathrm{~g} / \mathrm{cm}^{3}$. This number is expected to be a slight overestimate, since HiPco nanotubes are known not to pack in perfectly ordered bundles. Other densities were taken as $\rho_{\mathrm{PVA}}$ $=\rho_{\mathrm{PVP}}=1.30 \mathrm{~g} / \mathrm{cm}^{3}, \rho_{\mathrm{PS}}=1.05 \mathrm{~g} / \mathrm{cm}^{3}$, and $\rho_{\mathrm{Fe}}=7.8 \mathrm{~g} / \mathrm{cm}^{3}$.

${ }^{11}$ U. D. Venkateswaran, A. M. Rao, E. Richter, M. Menon, A. Rinzler, R. E. Smalley, and P. C. Eklund, Phys. Rev. B 59, 10928 (1999).

${ }^{12}$ J. N. Coleman, K. P. Ryan, M. S. Lipson, A. Drury, M. Cadek, M. in het Panhuis, R. P. Wool, and W. J. Blau, AIP Conf. Proc. 633, 557 (2002).

${ }^{13}$ K. P. Ryan, S. M. Lipson, S. M. O'Flaherty, V. Barron, M. Cadek, A. Drury, H. J. Byrne, R. P. Wool, W. J. Blau, and J. N. Coleman, Proc. SPIE 4876, (2002).

${ }^{14}$ B. P. Grady, F. Pompeo, R. L. Shambaugh, and D. E. Resasco, J. Phys. Chem. B 106, 5852 (2002). 